\title{
Os não agraciados com o Prêmio Nobel de Literatura
}

\section{Benedict Anderson}

\section{Resumo}

A distribuição do Prêmio Nobel de Literatura pode ser vista como reflexo da conjuntura geopolítica mundial. O autor analisa os agraciados com a premiação em três épocas distintas: 1901-1939, Guerra Fria e pós-Guerra Fria. Tal estudo revela padrões e desvela nuances políticas e ideológicas que pautam a concessão do Prêmio.

Palavras-chave: Prêmio Nobel de Literatura; Não Agraciados; Línguas Nacionais.

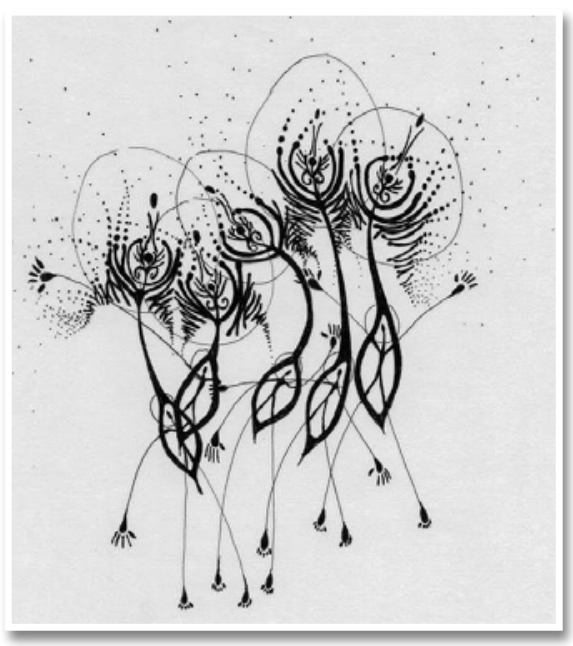

The unrewarded of the Nobel Prize for Literature

\section{Benedict Anderson}

Professor emérito de Estudos Internacionais da Universidade de Cornell e membro da Academia Americana de Artes e Ciências.

\begin{abstract}
The concession of the Nobel Prize for Literature can be seen as a result of the world geopolitical conjuncture. The author analyses the rewarded with the prize in three distinct moments: 19011939, Cold War and post-Cold War. Such study reveals patterns and unveils political and ideological nuances which guide the concession of the Prize.
\end{abstract}

Keywords: Nobel Prize for Literature; Unrewarded; National Languages. 


\section{A HISTÓRIA DO PRÊMIO'}

A decisão de conferir o Prêmio Nobel de Literatura de 2012 para o novelista chinês Mo Yan provoca, mais uma vez, o questionamento sobre os critérios de atribuição dessas láureas a partir de uma perspectiva global. Em quase todos os países, de modo evidente, a concessão de prêmios literários tem sido previsivelmente contaminada pelo cenário das políticas nacionais, a formação de restritos e exclusivistas "grupos literários", convicções religiosas, preconceitos raciais, conflitos de nacionalidade e ideologias do período. Teria sido essa a razão de, em mais de 110 anos de anúncios de ganhadores do Prêmio Nobel de Literatura, não ter havido nenhum agraciado de qualquer dos países do Sudeste Asiático - enquanto cada uma das outras regiões teve seu momento?

A história do Prêmio pode ser dividida em três partes: a era de dominação mundial das potências da Europa Ocidental, a era da Guerra Fria e a contemporânea era da globalização. Durante o primeiro período, entre 1901 e 1939, quase todos os prêmios foram para escritores da Europa Ocidental, distribuídos da seguinte maneira: seis para a França; cinco para a Alemanha; e três para cada um dos que seguem: Suécia, Itália, Noruega e Estados Unidos. Reino Unido, Espanha, Polônia, Irlanda e Dinamarca tiveram dois para cada um, e houve ainda os solitários representantes de Bélgica, Finlândia, Rússia, Suíça e Índia (Tabela 1). Assim, o favoritismo regional estava, totalmente evidente - escandinavos tomaram um terço dos prêmios. Dentre eles apenas o norueguês Knut Hamsun estaria entre os mestres da humanidade. Tagore, da Índia colonial, constituiria uma interessante singularidade, o único vencedor do Prêmio (1913) a representar uma colônia e estrela solitária da Ásia até 1968, quando o japonês Kawabata obteve também tal sucesso. Estadunidenses apenas começaram a receber os prêmios nos turbulentos anos 1930, dois deles depois de Hitler ascender ao poder, entretanto com qualidade discutível. No

1 Apresenta-se aqui uma versão expandida do prefácio a: MANAF, Nor Faridah Abdul; QUAYUM, Mohammad (Eds.). Imagined communities revisited: critical essays on Asia-Pacific literatures and cultures. Kuala Lumpur, 2011, também publicado na New Left Review, n. 80, mar./abr. 2013. 
mesmo período, um importante país europeu era enfaticamente e discriminado, Rússia/URSS: Previamente à Revolução de Lênin, a discriminação estava baseada na tradicional rivalidade sueca, e em seu descontentamento com a Rússia imperial; depois de 1919, o comunismo se tornou o ponto mais crítico. Sintomaticamente, o único agraciado russo, Ivan Bunin, vivia exilado em Paris. Nos últimos anos do czarismo, o clássico gigante Tolstoi foi ignorado, talvez por conta da sua radical postura política "anarquista", assim como Tchecov e o poeta Aleksandr Blok. Posteriormente, o grande dramaturgo Bulgakov, os poetas Mayakovsky e Mandelstam, e os romancistas Gorky, Andreev e Zamyatin foram todos desprezados.

\section{Tabela 1 - Distribuição dos Prêmios Nobel de Literatura, 1901-2012}

\begin{tabular}{|c|c|l|}
\hline $\begin{array}{c}\text { No. de } \\
\text { Prêmios }\end{array}$ & País & \multicolumn{1}{c|}{ Laureados } \\
\hline \multirow{2}{*}{$\mathbf{1 9 0 1}-\mathbf{1 9 3 9}$} & França & $\begin{array}{l}\text { Prudhomme, Mistral, Rolland, } \\
\text { France, Bergson }\end{array}$ \\
\hline 5 & Alemanha & $\begin{array}{l}\text { Mommsen, Eucken, Heyse, } \\
\text { Hauptmann, Mann }\end{array}$ \\
\hline 3 & $\begin{array}{c}\text { Suécia / Itália / Noruega / } \\
\text { Estados Unidos }\end{array}$ & $\begin{array}{l}\text { / Carducci, Deledda, Pirandello } \\
\text { / Bjørnson, Hamsun, Undset / } \\
\text { Lewis, O'Neill, Buck }\end{array}$ \\
\hline 2 & $\begin{array}{c}\text { Reino Unido / Espanha / } \\
\text { Polônia / Irlanda / Dinamarca }\end{array}$ & $\begin{array}{l}\text { Kipling, Galsworthy / Echegaray, } \\
\text { Benavente / Sienkiewicz, } \\
\text { Reymont / Yeats, Shaw / } \\
\text { Gjellerup, Pontoppidan }\end{array}$ \\
\hline 1 & $\begin{array}{c}\text { Bélgica / Finlândia / Rússia / } \\
\text { Suíça / Índia }\end{array}$ & $\begin{array}{l}\text { Maeterlinck / Sillanpää / Bunin } \\
\text { / Spitteler / Tagore }\end{array}$ \\
\hline
\end{tabular}




\begin{tabular}{|c|c|c|}
\hline & $1944-1991$ & \\
\hline 6 & França & $\begin{array}{l}\text { Gide, Mauriac, Camus, Perse, } \\
\text { Sartre, }{ }^{*} \text { Simon }\end{array}$ \\
\hline 5 & Estados Unidos & $\begin{array}{l}\text { Faulkner, Hemingway, Steinbeck, } \\
\text { Bellow, Singer }\end{array}$ \\
\hline 4 & Reino Unido / URSS & $\begin{array}{l}\text { Eliot, Russell, Churchill, Golding } \\
\text { / Pasternak, Sholokhov, } \\
\text { Solzhenitsyn, Brodsky }\end{array}$ \\
\hline 3 & Suécia / Alemanha / Espanha & $\begin{array}{l}\text { Lagerkvist, Johnson, Martinson } \\
\text { / Hesse, Sachs, Böll / Jiménez, } \\
\text { Aleixandre, Cela }\end{array}$ \\
\hline 2 & Itália / Chile / Grécia & $\begin{array}{l}\text { Quasimodo, Montale / Mistral, } \\
\text { Neruda / Seferis, Elytis }\end{array}$ \\
\hline \multirow[t]{2}{*}{1} & $\begin{array}{c}\text { Polônia / Dinamarca / Irlanda } \\
\text { / Islândia / Iugoslávia / } \\
\text { Israel / Guatemala / Japão } \\
\text { / Austrália / Bulgária / } \\
\text { Colômbia / Tchecoslováquia } \\
\text { / Nigéria / Egito / México / } \\
\text { África do Sul }\end{array}$ & $\begin{array}{l}\text { Miłosz / Jensen / Beckett / } \\
\text { Laxness / Andric' / Agnon / } \\
\text { Asturias / Kawabata / White } \\
\text { / Canetti / García Márquez / } \\
\text { Seifert / Soyinka / Mahfouz / } \\
\text { Paz / Gordimer }\end{array}$ \\
\hline & $1992-2012$ & \\
\hline 3 & Reino Unido & Naipaul, Pinter, Lessing \\
\hline 2 & Alemanha / China & Grass, Müller / Gao, Mo \\
\hline 1 & $\begin{array}{l}\text { Santa Lucia / Estados Unidos } \\
\text { / Japão / Irlanda / Polônia } \\
\text { / Itália / Portugal / Hungria } \\
\text { / África do Sul / Áustria / } \\
\text { Turquia / França / Peru / } \\
\text { Suécia }\end{array}$ & $\begin{array}{l}\text { Walcott / Morrison / Oe / } \\
\text { Heaney / Szymborska / Fo / } \\
\text { Saramago / Kertész / Coetzee } \\
\text { / Jelinek / Pamuk / Le Clézio / } \\
\text { Vargas Llosa / Tranströmer }\end{array}$ \\
\hline
\end{tabular}

* Sartre foi agraciado com o Prêmio em 1964, porém o recusou. 
Composto por cinco dos dezoito membros da conservadora Academia Sueca de Literatura, o Comitê Nobel de Literatura é uma instituição real que se autoperpetua com membros que servem de modo vitalício, com a obrigação precípua de preservar e incrementar "a pureza, o vigor e a majestade" da língua sueca. O Comitê prepara uma lista prévia elaborada com base nas nomeações de relevantes instituições acadêmicas e literárias de todo o mundo, assim como da própria Academia e seus laureados vivos, para uma conclusiva decisão majoritária, em sessão plenária, entre os dezoito membros. De modo esperado, então, o gosto literário da Academia foi habitualmente conservador. Seus membros não deram muita atenção para poetas surrealistas ou grandes modernistas experimentais como Proust, Joyce, Musil, Brecht, Rilke, Cafavy, Benjamin, Roth (Joseph), Woolf, Lorca, ou o próprio impactante dramaturgo sueco August Strindberg. ${ }^{2}$ As dedicações póstumas do Nobel a trabalhos com um "ideal" ou uma inclinação "idealista" também não desqualificaram alguns desses trabalhos, além de outros como Ibsen ou Zola, Hardy, Lawrence ou Dreiser - e ao mesmo tempo ajudaram a delinear um dos gêneros mais medíocres da literatura do século XX, a própria menção do Nobel, com o seu insípido humanismo entregue a amontoados de clichês que envergonhariam as páginas literárias de qualquer respeitável jornal interiorano. Além do mais, deve-se ainda computar que, nos anos em discussão, a competência linguística do Comitê manteve-se significativamente limitada, pois traduções de trabalhos literários recentes provenientes de línguas não europeias ocorreram em número bastante pequeno. Esse obstáculo estrutural seguramente explica o porquê de a China (Lu Hsün, por exemplo, ou Lu Ling) e o Japão (Soseki, Akutagawa, Tanizaki) não serem candidatos plausíveis para os prêmios.

2 A opinião pública na Suécia se chocava à da Academia, e em 1912 Strindberg foi premiado, o que acabou ficando conhecido como o Prêmio Anti-Nobel, com um montante de 50 mil coroas suecas levantadas de pequenas contribuições em um apelo popular para condecorar o dramaturgo, um ardoroso anarquista que em 1884 esboçou um plano para assassinar o rei sueco. O prêmio foi criado pelo líder social democrata, Hjalmar Branting, seguindo uma mobilização popular de trabalhadores para o aniversário de 36 anos de Strindberg (ROBINSON, Michael (Ed./Transl.). London, Strindberg's Letters, 1992. v. 2, p. 790. 
A era da Guerra Fria exibiu padrões bem diferentes. Não foram concedidos prêmios entre 1940 e 1943, os anos decisivos da Segunda Guerra Mundial. Mas de 1944 em diante, o Comitê foi inevitavelmente afetado pelo colapso do imperialismo europeu e pela disputa entre a União Soviética e os Estados Unidos pela preeminência mundial, o que dividiu a Europa em dois blocos hostis. Colônias até podiam ser ignoradas, mas não nações recém-independentes com assento na Assembleia Geral da ONU. O orgulho da Europa em sua superioridade cultural ante os "provincianos" Estados Unidos, e na nova era do seu próprio declínio político e econômico, levou-a a um intenso desejo de reforçar especialmente em Londres e Paris - a tradução e a publicação de importantes textos estrangeiros. Nesse período a postura sueca foi sensivelmente diferente da dos anos antecedentes à guerra. O país se manteve neutro entre o Eixo e as Forças Aliadas, enquanto a Dinamarca e a Noruega estavam ocupadas por tropas nazistas, e essa sua neutralidade promoveu o ressentimento dos vitoriosos aliados de 1945. Os horrores cometidos pelo regime de Hitler em nome do racismo e da superioridade ariana comprometeram o prestígio de nacionalismos conservadores (incluindo literatura conservadora) em toda a Europa. Durante boa parte da Guerra Fria, a Suécia redesenhou sua neutralidade em significativas novas maneiras. O país desenvolveu a mais avançada sociedade social democrata do mundo e tentou se apresentar como uma terceira via entre o inescrupuloso capitalismo americano e o inescrupuloso socialismo do estado soviético. Assim, a aproximação com os países do Terceiro Mundo foi uma boa maneira para construir a nova reputação sueca como uma esquerda moderada, um país pacifista, especialmente fecundo de altos oficiais para as Nações Unidas.

Entre 1944 e 1991, cinquenta Prêmios Nobel de Literatura foram concedidos, e sua distribuição foi claramente diferente daquela da era precedente. Quinze países tinham ganhado prêmios entre 1901 e 1939, enquanto 28 o receberam durante a Guerra Fria. A França, com seis vencedores (ainda que Sartre o tenha recusado), continuou a Primeira Colocada, mas por pouco. Depois vieram os Estados Unidos com cinco, o Reino Unido e a União Soviética, com 
quatro cada um; Suécia, Alemanha e Espanha com três; e Itália, Chile e Grécia com dois. Vencedores únicos vieram da Polônia, Dinamarca, Irlanda, Islândia, Iugoslávia, Israel, Guatemala, Japão, Austrália, Bulgária, Colômbia, Tchecoslováquia, Nigéria, Egito, México e África do Sul. Com base nessa listagem pode-se verificar o acentuado declínio do bloco escandinavo do pré-guerra.

Entretanto, o olhar de Estocolmo se estendeu agora para o Leste Asiático, o Oriente Médio, as Américas do Sul e Central, a África e a Austrália - apenas o Sudeste Asiático continuava ainda invisível. A política do Comitê havia mudado em alguns aspectos importantes. A primeira coisa a notar é que continuava a discriminar autores conservadores: Céline e Malraux na França, Borges na Argentina, Mario Vargas Llosa (perdoado apenas em 2010), Evelyn Waugh e Anthony Powell, por exemplo. A ridícula exceção foi Winston Churchill. E, ainda, esquerdistas independentes como Sartre, e até mesmo comunistas como Pablo Neruda, eram considerados, desde que não fossem provenientes da União Soviética ou do Partido Comunista Russo. Caso isolado foi o de Sholokhov, ocorrido exatamente após a abertura dos anos Khrushchov: os outros três russos eram dissidentes e/ou exilados.

A outra grande mudança aconteceu no quadro comparativo dos idiomas. No mundo do pré-guerra, alemão, francês e inglês eram os idiomas de maior prestígio na vida cotidiana e na "literatura mundial". Porém, após 1945, a Alemanha foi dividida em duas, e a germanofobia estava em todo lugar. Enquanto, o prestígio linguístico do francês entrava em um lento declínio, o "inglês" em suas variadas formas consolidava sua esmagadora hegemonia mundial. É surpreendente que, embora a França continuasse no topo dos vencedores do Prêmio, nenhum dos campeões veio do anterior império ultramarino na Indochina, oeste africano, Magreb ou Caribe. Por sua vez, domínios britânicos e antigas colônias se saíram muito bem: White pela Austrália, Beckett e depois Heaney pela Irlanda, Soyinka pela Nigéria, Nadine Gordimer (e depois Coetzee) pela África do Sul e, por fim, Derek Walcott pelas Índias Britânicas Ocidentais (Santa Lucia). Autores que estavam exilados ou imigrados nos Estados Unidos ou no Reino Unido também escreveram em inglês - Miłosz, que desertou para o Ocidente 
trinta anos antes de receber o Prêmio; Brodsky; Canetti, que deixou a Bulgária e foi para a Inglaterra aos seis anos de idade; e assim por diante. Uma continuidade com a era precedente, todavia, foi a negligência ou a ignorância em relação as autores consideravelmente admirados por críticos atuais de muitos países: por exemplo, o japonês Abe Kobo, os russos Nabokov e Akhmatova, o anglo-americano Auden e o inglês Graham Greene.

No último quarto de século da era pós-Guerra Fria, podem-se notar algumas interessantes novidades. Primeiramente, o fim da autoridade francesa (um prêmio), da hegemonia estadunidense (um prêmio) e do prestígio russo (nenhum prêmio). Os ganhadores com apenas um prêmio foram as Índias Britânicas Ocidentais, os Estados Unidos, o Japão, a Polônia, a Itália, Portugal, a Hungria, a África do Sul, a Áustria, a Turquia, a Irlanda, a França, o Peru e... a Suécia. As exceções são uma reunificada Alemanha (dois prêmios: Günter Grass e Herta Müller, mas não Hans Magnus Enzensberger) e a China (também com dois, Mo Yan e Gao Xingjian - ainda que este último, vencedor em 2000, tenha se estabelecido na França no final dos anos 1980). O Reino Unido esteve na liderança, com três prêmios - no entanto, dos vencedores britânicos, apenas Harold Pinter era nativo, enquanto V. S. Naipaul precipitou-se das Índias Ocidentais e Doris Lessing crescera na Rodésia.

\section{CURIOSO ESPAÇO ABERTO}

E o Sudeste Asiático? Estruturalmente, a região tem sido excepcionalmente diversificada - nenhum idioma dominante, nenhuma religião unânime, nenhuma hegemonia política. Na era colonial, alguns dos seus setores foram governados por imperialismos da Inglaterra, da França, da Holanda, da Espanha, de Portugal e dos Estados Unidos. Gabriel García Márquez pôde representar, majoritariamente, hispanófonas e católicas Américas do Sul e Central, Walcott as ilhas caribenhas (ex-britânicas), Tagore o Sul Asiático (também ex-britânico), Naguib Mahfouz o Oriente Médio Islâmico, Wole Soyinka a África (onde o imperialismo britânico era o mais poderoso) e talvez Orhan Pamuk a Turquia europeia. Mas nenhum escritor do Sudeste Asiático pôde pretender se constituir como um símbolo da região como um todo. Durante a Guerra Fria, o Sudeste 
Asiático foi surpreendentemente rasgado por ideologias e golpes militares. Quase todos os seus Estados experimentaram longos períodos de conflitos armados entre comunistas e anticomunistas - culminando em ditaduras de direita ou militares nas Filipinas, na Tailândia, Indonésia, Cingapura e Birmânia, e três bem-sucedidos governos comunistas na Indochina.

Ao longo do século XX houve significativa perda da "grande língua" na região. Os Estados Unidos se asseguraram de quase fazer desaparecer o espanhol nas Filipinas, a Indonésia, rapidamente dispensou o holandês, a militarizada Birmânia livrou-se do inglês e a Indochina afastou-se do francês por duas gerações. O contraste com a África é espantoso: muitos dos Estados ex-colônias desse continente assumiram os idiomas coloniais como línguas oficiais, embora promovendo idiomas locais como símbolos de nacionalismos particulares. Por esta razão, os escritores do Sudeste Asiático provavelmente não tiveram ardorosos simpatizantes na Europa, no Hemisfério Ocidental ou até mesmo no mundo islâmico. Uma curiosidade final é digna de nota: a Indonésia, de longe o maior Estado-nação no Sudeste Asiático, foi colonizada pela Holanda, o menor e menos importante dos poderes imperialistas europeus, com um idioma utilizado apenas por seus próprios cidadãos. Pior, ou melhor, ainda, a Holanda nunca venceu um Prêmio Nobel de Literatura, compondo um grupo com outros perdedores permanentes europeus, tais como Albânia e Romênia (no caso de Canetti ser contabilizado pela Bulgária). Deste modo, o Hague não se encontrava em posição de fazer um lobby pela Indonésia, ainda que assim o desejasse.

Alguém poderia supor que aquelas grandes potências coloniais iriam auxiliar os escritores das suas possessões anteriores. Porém, Paris estava mais interessada nos antigos territórios franceses, o Oeste africano, o Magreb e o Caribe do que no remoto Vietnam que destroçou os franceses em uma longa e devastadora guerra de libertação. Os Estados Unidos, sempre marcados por um complexo de inferioridade cultural em relação à Europa, preferiram contabilizar como "americanos" vencedores do Prêmio aqueles exilados cujas credenciais literárias já eram bastante elevadas e que haviam obtido sua cidadania estadunidense (Miłosz da 
Polônia, Brodsky da Rússia). As Filipinas foram completamente ignoradas ou menosprezadas, ainda que sua língua predominante fosse o "inglês americano". Londres teve muitas diferentes opções por conta do tamanho e da amplitude do antigo império, muitas ex-colônias (Austrália, África do Sul, Canadá, Nova Zelândia) bem como Nigéria, Gana, Índia, Caribe, Paquistão, etc. - de modo que Malásia e Cingapura, embora conservando o inglês como línguas de Estado, não foram vistos como importantes.

O que dizer dos efeitos da nacionalização linguística no Sudeste Asiático? Várias dessas nacionalizações foram feitas com a finalidade de alcançar solidariedade nacional, mas quase sempre as decisões sobre quais línguas deveriam se tornar "nacionais" tiveram como efeito favorecer o poder restrito de grupos linguísticos, demográficos e políticos específicos. Birmaneses e vietnamitas tiveram todas as cartas em suas mãos - boas estatísticas, densidade geográfica, educação superior, poder político - assim, a decisão de nacionalizar o birmanes e o vietnamita seria "natural", ainda que isso pudesse significar a marginalização de muitos "grupos minoritários". Bangcoc não possuía uma dominância "natural", desse modo, a imposição de um "modelo tailandês" apenas poderia ser conseguida por vias autoritárias. Com o final da colonização estadunidense, o maior grupo linguístico das Filipinas falava vários dialetos do cebuano, mas a língua tagalo, falada por pessoas da capital e regiões vizinhas, teve de ser imposta por coerção, com resultados variados. A resistência veio de diferentes regiões, ou em favor do cebuano ou do inglês como "língua franca". Na Malásia, o malaio também teve de ser imposto pelos grupos políticos dominantes, porém houve resistência de grupos chineses, indianos e do Bornéu do Norte, que falavam respectivas quer línguas estrangeiras (chinês, indiano) quer a "língua franca" (inglês).

O único país a construir uma incontestável língua nacional que também é a "língua franca" foi a Indonésia. Em termos literários, é difícil encontrar qualquer importante escritor indonésio que automaticamente não utilize o bahasa indonésia, não obstante existam inflexões regionais. A língua não favoreceu nenhum grupo em especial. Consequentemente se observa a variedade étnica da literatura nacional: Kwee Thiam Tjing (Hokkien Chinês), Iwan 
Simatupang (Toba Batak), Chairil Anwar (Medan Minangkabau), Amir Hamzah (Malaio), Pramoedya Ananta Toer (Javanês), Eka Kurniawan (Sudanês), Putu Widjaja (Balinês), entre outros. Da minha limitada experiência, julgo a Indonésia, em termos literários, o mais criativo país do Sudeste Asiático precisamente por conta da mistura da língua franca e da língua nacional por uma via não autoritária. Em contraste, a imposição coercitiva (por políticos e burocratas filisteus) encorajou um obtuso tipo de neotradicionalismo assim como uma rejeição hostil. Por esta razão, significativos grupos minoritários preferiram escrever em inglês, tanto com o objetivo de rejeitar o neotradicionalismo, quanto de obter uma possível simpatia da opinião pública internacional.

Contudo, a nacionalização de qualquer tipo também significa uma espécie de reclusão. Nenhuma das línguas nacionais do Sudeste Asiático possui uma aura transnacional. O sistema global se certificou de que o birmanês, o vietnamita, o laociano, o tailandês, o khmer, o tagalog e até mesmo o malaio se restringissem apenas a seus "falantes" locais. Até mesmo no caso do bahasa indonésia e do bahasa melayu, que são línguas de uma mesma família, indonésios raramente leem literatura malaia que eles pensam ser provincial e desusada, semelhante a algo étnico - enquanto os malaios da Malásia tendem a entender o indonésio da Indonésia como um caótico amálgama de variadas línguas. Assim, nenhuma provável solidariedade há no semblante de Estocolmo. Reclusão também significa que qualquer chance de obter um Prêmio Nobel requer tradução para as "grandes línguas" que os suecos dominam. No entanto, as controladoras elites de nacionalistas filisteus obviamente não leem boas obras literárias, e raramente consideram a possibilidade de prepararem bons tradutores. A tradução não é entendida como uma arte, apenas uma técnica. Uma das razões por que grandes escritores latino-americanos conseguem o Prêmio Nobel se deve ao fato de possuírem um grupo de bilíngues de primeira classe (espanhol-inglês), tradutores profissionais que têm sido largamente premiados. Como região, e como um grupo de países isolados, o Sudeste Asiático não possui nada semelhante. 


\section{PROVÁVEIS AGRACIADOS}

Houve em algum momento plausíveis candidatos do Sudeste Asiático aptos aos Prêmios Nobel? Não sou competente o suficiente para afirmar algo decisivo sobre isso. O herói nacional das Filipinas, José Rizal - certamente a maior figura literária proveniente daquele país - foi executado por espanhóis em 1896, cinco anos antes de o Prêmio Nobel começar a ser distribuído. Se tivesse vivido até os 60 anos de idade, teria tido ele uma chance? Penso que não, ainda que tenha escrito em uma das "importantes" línguas, até por conta de nenhum sério escritor anti-imperialista de qualquer colônia ser aceitável até depois da Segunda Guerra Mundial (e os Prêmios Nobel somente são concedidos a escritores vivos). A maravilhosa poética místico-islâmica criada pelo aristocrata medan malaio Amir Hamzah, nos anos 1930, jamais poderia ter sido levada a sério em Estocolmo, além de ele precocemente ter "partido", morto por criminosos "revolucionários", no primeiro ano depois da declaração de independência da Indonésia. Seu trabalho é excepcionalmente difícil de traduzir, não somente por sua determinação religiosa, como também - até onde eu sei - por nunca ter sido traduzido por um profissional. Nem o Estado colonial holandês, nem a República da Indonésia fizeram muito pelo seu reconhecimento. Mas é possível imaginar que, traduzido para o francês ou o inglês, os poemas poderiam, a princípio, ser contemplados na era do pós-Guerra Fria - se apenas ainda estivesse vivo.

A última "possibilidade" seria Pramoedya Ananta Toer, cujo nome começou a ser esboçado por seus promotores na Europa no início dos anos 1980. Nenhum agraciado negaria o fato de Pramoedya ser facilmente considerado o maior escritor de prosa no bahasa indonésia, com assombrosa produção de novelas, contos, peças e ensaios de crítica literária em um período de quarenta anos, exatamente entre 1948-1988. Caso alguém tentasse explicar o porquê de ele ter sido repetidamente postergado pelo Comitê de Estocolmo se poderiam elencar inúmeros argumentos. Primeiramente e mais importante, sua postura política como ativista na revolução indonésia pela independência, e depois como um esquerdista independente que escreveu majoritariamente no universo do socialismo realista. Durante o início dos 
anos 1960, ele regularmente atacou colegas conservadores e liberais - escritores indonésios e outros intelectuais, por sua política reacionária e suas ligações ao Ocidente. Grande número dos seus escritos foram rapidamente traduzidos para o chinês, o russo e algumas línguas menores do Leste Europeu e da União Soviética. Mas ainda que ele tivesse sido traduzido para o inglês, jamais teria sido aceito em Estocolmo, no mínimo, por conta do Partido Comunista da Indonésia (do qual em verdade Pramoedya não era membro), o maior partido comunista fora do bloco comunista.

Alguns poderiam pensar que as chances de Pramoedya teriam aumentado em 1980, por ter passado de 1966 a 1979 no arquipélago de prisões criado pelo ditador Suharto em seguida ao vasto massacre de comunistas e "comunistas" entre 1965 e 1966. Contudo, dentro da prisão se desdobrou para escrever o famoso Quarteto Buru de novelas, ao longo dos seus anos no campo de concentração na remota ilha de Buru. De fato, todos os seus numerosos trabalhos foram banidos durante os trinta e dois anos do regime Suharto, e até hoje estão tecnicamente no ostracismo, embora o banimento raramente seja praticado. Entretanto, até onde posso dizer, nunca houve um vencedor do Nobel que passou mais tempo preso (sem jamais ter sido julgado por um crime). Também é provável que Pramoedya tenha sido mal servido por velhos amigos que decidiram divulgar precipitadamente uma tradução em inglês do Quarteto Buru, essencialmente por razões humanistas e políticas, feita por um ativista australiano que não tinha competência para a tarefa. O estilo da prosa de Pramoedya é incomum em relação a qualquer outro autor indonésio, e seu humor negro é especialmente difícil de traduzir para o inglês. Além do mais, as maiores das suas obras - suas coletâneas de contos dos anos 1950 - permanecem não traduzidas. Terminada a Guerra Fria ele ganhou um Prêmio Magsaysay (1995) e o maior Prêmio Fukuoka (2000), mas ambos foram recebidos com rancorosa hostilidade pela classe dirigente indonésia e muitos dos seus literatos e intelectuais anticomunistas. Apenas depois da sua morte ele passou a ser aceito como o maior escritor moderno do seu país. Muito tarde para Estocolmo ... 